\title{
Courseware for observational research (COR): A new approach to teaching naturalistic observation
}

\author{
DAWN G. BLASKO, VICTORIA A. KAZMERSKI, ERIC W. CORTY, and CARL A. KALLGREN \\ Penn State Erie, The Behrend College, Erie, Pennsylvania
}

\begin{abstract}
Naturalistic observation is one of the most basic and widely used techniques of scientific research, yet it often receives only a cursory treatment in the research methods course. In this paper, we describe a new interactive multimedia software program that teaches interval, frequency, and duration coding with the use of brief digitized video clips and model check sheets. The program teaches basic observational techniques by leading students through the stages of developing a behavioral coding scheme, collecting data, establishing interrater reliability, and analyzing with chi square. It also has a laboratory component that allows students to practice their skills.
\end{abstract}

Courseware for Observational Research (COR) is a new interactive multimedia software program designed to teach methods of observational research from the initial phase of hypothesis generation through the final stage of data analysis and interpretation. The paper begins with a description of the program and an outline of the goals for the program. Then the development of the program and minimal system requirements for its use are described. Finally, the initial stages of evaluation of COR are discussed.

Systematic observation is important in many areas of psychology. In child development, it has been used to study a wide variety of issues, such as emotional expression (Eisenberg et al., 1989) and attachment (Belsky \& Rovine, 1988). It has been widely used in studies of animal behavior and in developing behavior plans in educational and clinical settings. Yet despite so many applications, observational methods receive little coverage in many research courses and textbooks.

Research methods courses are in general challenging for both students and faculty. Students often complain that the work is difficult, boring, and not applicable to careers in the "helping professions." Faculty must maintain academic standards while dealing with unhappy and unmotivated students, with the consequence that research courses often receive low student evaluations in comparison with other courses (Cashin, 1990). Yet despite these drawbacks, most faculty see research as a crucial part of

The authors would like to thank the Penn State Educational Technology design team for COR, and especially Carol Dywer, senior design specialist, and Morris Weinstock, main programmer. We would like to thank Michael Drabik and Colton Skorupan for their help with filming and digitizing and the students and faculty who have given us feedback that has allowed us to improve the program. Instructors interested in using COR should contact D. G. Blasko by e-mail at dawnblasko@psu.edu or by regular mail at Penn State Erie, the Behrend College, School of Humanities and Social Sciences, Station Road, Erie, PA 16583. psychology training; not only do students learn research techniques, such training also improves reasoning in real-world situations (VanderStoep \& Shaughnessy, 1997). Many schools have a tradition of teaching research methods by providing students with active, hands-on experience. Such approaches are widely recognized as having great value in encouraging diversity in learning styles and improving understanding (McGovern, 1993). However, these methods are often very expensive and time intensive, and they require a great deal of input from faculty, who often teach large course loads (Drake \& Stahl, 1995).

There are other challenges as well. The techniques of observational research cannot be mastered without considerable practice. In addition, there are ethical and financial concerns. Observation techniques are often taught with laboratory animals, but maintaining animals is expensive and requires special facilities and animal-care technicians (Graham, Alloway, \& Kramer, 1994). In addition, the use of animals for training purposes alone is ethically quesitionable to some people (Graham et al., 1994). These constraints prohibit many schools from maintaining animal labs. Alternatively, in some schools systematic observation methods are taught by observing children, but this too leads to practical dilemmas. It is often difficult to arrange for a suitable observation site, and obtaining permission from the children's parents can also be difficult. In the past, we have taught observational research by taking field trips to the local zoo, but this procedure too has constraints. First, animal behavior in field sessions is quite variable. If there is time for only one field session and the animals sleep through it, little can be learned except for the fact that field work can be frustrating. Second, time constraints make it hard for the increasing number of commuter and nontraditional students to attend extended field sessions outside of class time.

Some of these challenges can be met by taking advantage of the rapid advances in multimedia technology. 
Multimedia with music and animation can offer an engaging, enjoyable, motivating way to introduce students to observational research. It can eliminate many of the constraints described above. Financial and ethical concerns are greatly reduced by utilizing videos of naturally occurring behavior. Goolkasian (1996) discussed several advantages of multimedia. For example, it can present information in a gradual, sequential manner; it offers great precision and control; and it can customize learning for an individual student's needs. Working, nontraditional, and disabled students can participate. Its use can also be extended beyond the classroom to student labs, the WorldWide Web, or CD-ROM for home study. Because of these advantages, psychology software has proliferated (Stoloff $\&$ Couch, 1992). Yet, to our knowledge no one has developed a program to teach observational research, although computers have been used for years to score behavioral observations (e.g., The Observer; Noldus, 1997).

COR makes use of multimedia presentations to illustrate the steps involved in observational research. With carefully chosen digital-video clips and computer-timed intervals, instructors can discuss issues and immediately demonstrate them. For example, one of the most difficult concepts is the development of a precise operational definition. With digital video, the instructor can play a videotaped behavior frame by frame so that everyone can analyze one occurrence of the behavior (e.g., eating, pushing). Behaviors can be carefully selected to illustrate specific issues and concepts. In one 50-min class period, students can observe chimpanzees, children, and birdsand instructors can be certain that the subjects are awake for the observation!

COR was designed to meet several specific instructional goals:

1. To help students develop systematic observational research skills, including how to form a hypothesis, selection and use of an appropriate coding scheme, calculation of interrater reliability, and analysis of data by using chi square.

2. To help students develop critical thinking skills, such as problem solving, creative thinking, and weighing alternative points of view.

3. To help improve collaborative work skills. Working on a research project as a team helps students recognize and evaluate their own strengths and those of their peers and teaches them to provide both intellectual and emotional support to other members of the team.

\section{COURSEWARE DESCRIPTION}

COR has three major components: lessons, a library, and a student laboratory. Each is described below.

\section{Lessons}

The five lessons are designed to be used by an instructor in the classroom, with the videos and coding sheets on a projection system. The first lesson defines the topic of observational research. The second lesson includes the planning of an observation. Here the three main methods of recording observations are defined: frequency, duration, and interval. Each of these is illustrated by a video and a description of the method for coding the observation. Specifically, the frequency method is illustrated by the counting of the number of times a gorilla brings his hand to his mouth to feed; the duration method is shown by the measurement of how long a hamster runs in a wheel; the interval method is illustrated by the coding of whether or not a college student eats popcorn in a given time interval. The instructor has considerable flexibility in the use of the program. After presenting the video and operationally defining the behaviors to be observed, the instructor can play the video again with a blank coding sheet on the computer screen so that students can individually code at their desks. The video can also be played while a student codes on the computer coding sheet in front of the class in real time. Finally, the video can be played with the computer coding the behaviors in a timelinked fashion as they occur in the video. The instructor simply enters the answers in edit mode before the class. Sample screens from Lesson 2 of the program are shown in Figure 1.

The third lesson describes three sampling methods: time, individual, and event sampling. We used a single complex video of five children (ranging in age from 1 to 7 years) in free play. Once again the instructor has the option of playing the movies without a coding sheet, with a coding sheet revealed, with a student coding in front of the class, or with the computer coding the behaviors. Depending on the level of the particular class, more or less repetition and detail may be used.

The fourth lesson covers one of the most difficult issues in observational research, the need to assess interrater reliability. Two methods are demonstrated, percent agreement and Cohen's kappa. Two observers separately code behaviors from the video of children playing. Using data from either the instructor or the class, the program steps students through the process of building a confusion matrix and calculating interrater reliability according to the two methods. See Figure 2 for a sample screen.

The final lesson covers data analysis. A video of two male college students eating popcorn is shown to the students (the same that is shown for interval coding). A hypothesis is given that one student, the owner of the room, will eat more popcorn than will the other student. The video is coded with the use of a combination of frequency and interval methods. Students are then taught to use chisquare analysis to test the hypothesis with the data collected from the video. Because of limited time and space, only one type of statistical analysis, chi square, is demonstrated at this time.

\section{Laboratory}

The laboratory component of the program is designed to be used by pairs of students to complete a hands-on 

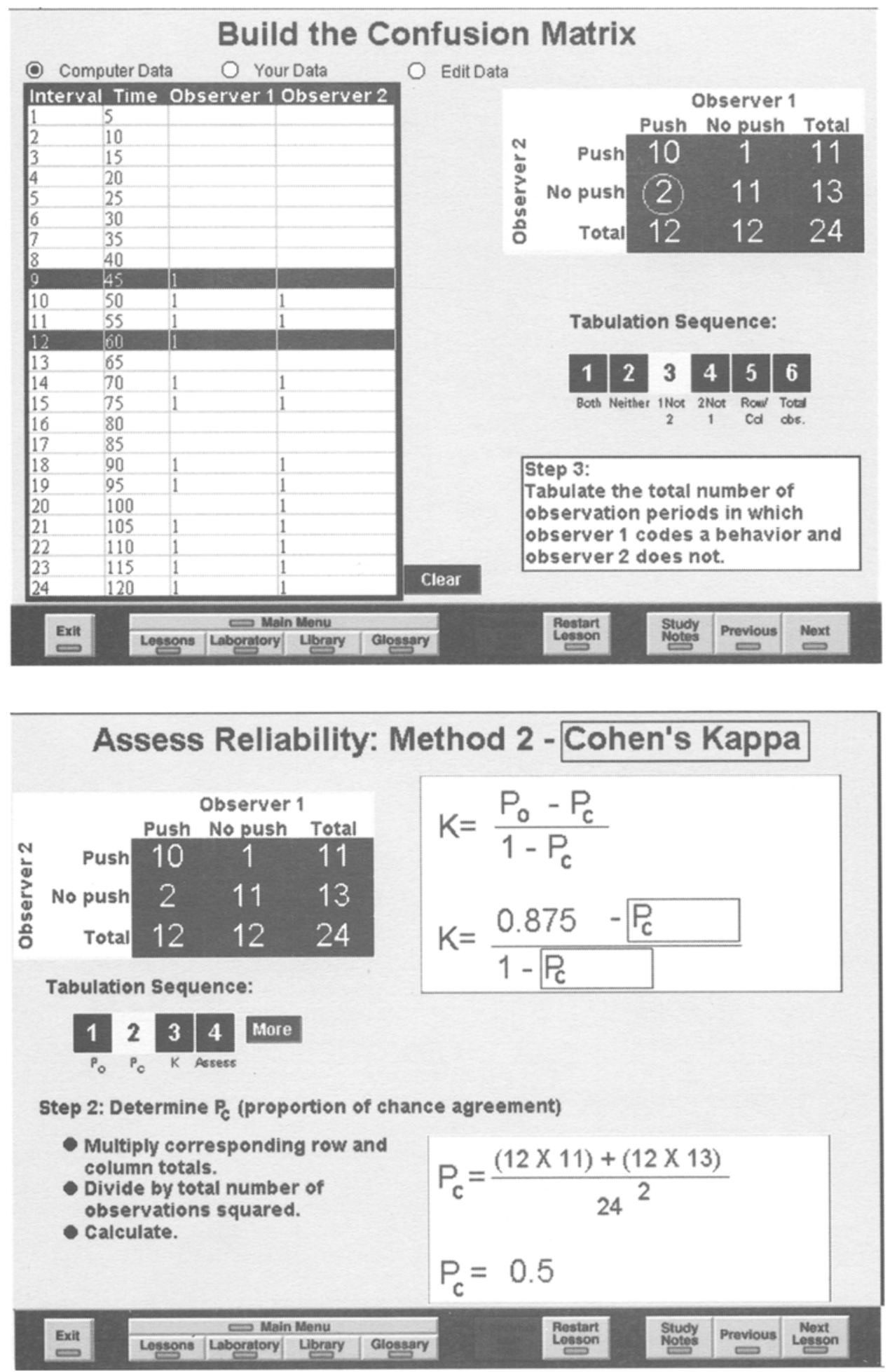

Figure 1. Sample computer screens showing the arrangement for video display and coding sheets for interval and frequency coding methods.

collaborative assignment. At our school, the program is installed on the computers in the Psychology Laboratory. The program prompts students through the steps of observational research. Each pair of students plans their observations by selecting from a choice of five videos to observe (children at quiet play; college students between classes; flamingos eating and preening; tropical fish; and spider monkeys). The program then prompts the students 

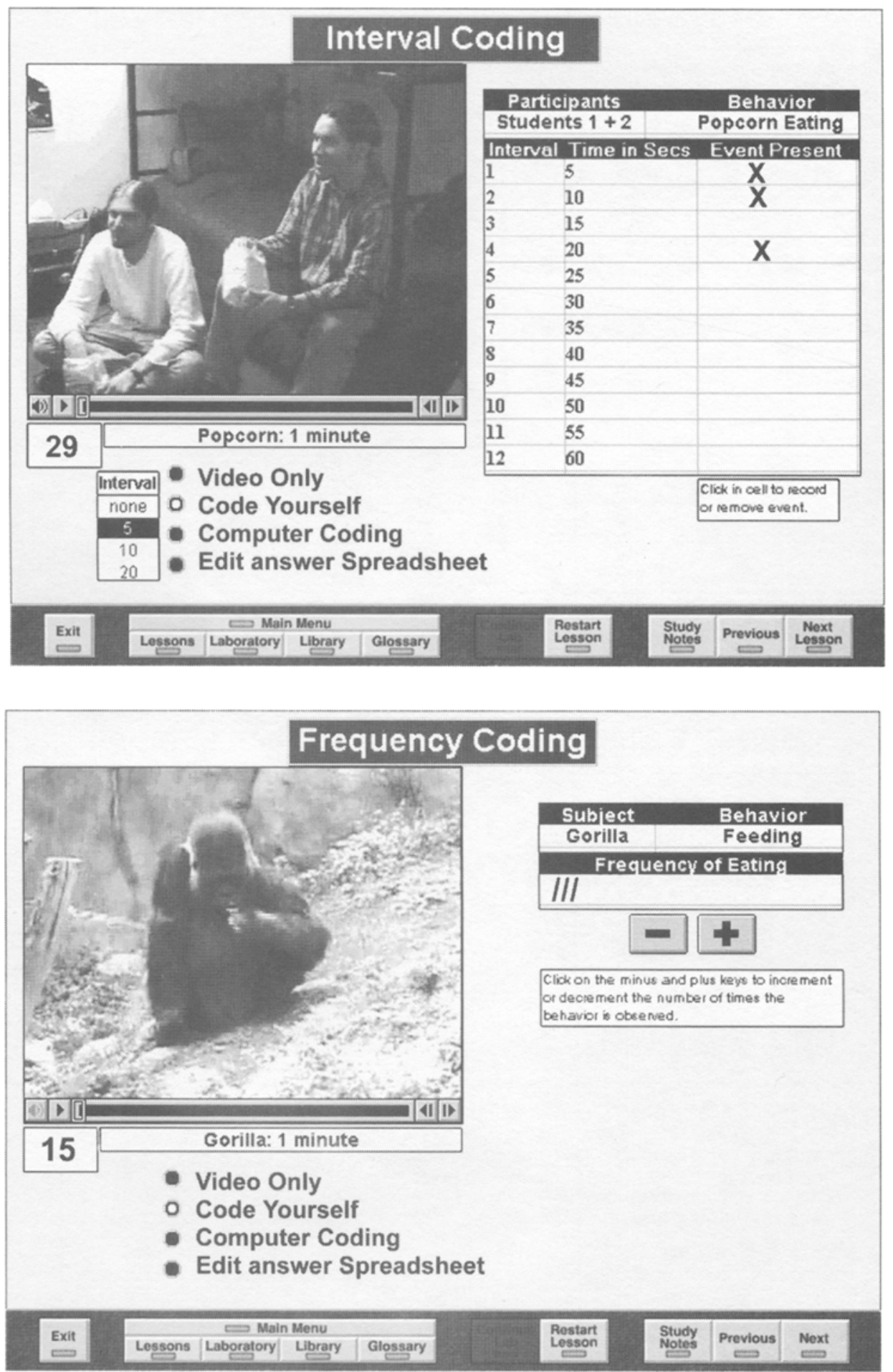

Figure 2. Sample computer screens showing the confusion matrix and some of the steps necessary to complete Cohen's kappa for assessing interrater reliability.

to develop a hypothesis, define behavioral coding categories, carry out the observation, and calculate interrater reliability. The lessons are available for students to review at any time. Links are provided throughout the lab- oratory to the appropriate lessons. At this time, we are requiring students to submit their work on paper. Future innovations may allow for submission of coding sheets and data analysis electronically. 


\section{Library}

The final component of the program is the library. Here the video segments from both the laboratory and lesson components can be viewed directly. There is also background information on the subjects of the videos, and there are interviews with some of the caretakers of the video subjects. A glossary defining many of the important terms used in the program is accessible with a button at the bottom of the screen, and it is also hot linked to the terms as they appear throughout the program.

\section{COURSEWARE DEVELOPMENT AND SPECIFICATIONS}

The development of COR was jointly funded by Penn State Behrend and Pennsylvania State's Educational Technology Center. The development machine was a Pentium 166 with $64 \mathrm{MB}$ of RAM. In the development of digital video applications, both the quality of the initial video and input device are critical. For this, a Miro DC20 capture card was used, because it provided good quality for a reasonable price. A Sony digital camcorder was used to record the movies. The choice of appropriate authoring software is an important decision as well, because it determines the functionality, ease of programming, and upgradability of the resulting program (see Rosen \& Petty, 1996, for a review of some available software). Our team decided on Oracle Media Objects $(\mathrm{OMO})$ as our primary authoring software because it is cross platform and allows the use of dynamic spreadsheet links. The use of OMO allowed for the design of interactive coding sheets that allow faculty and students to enter their own data and use it for future lessons.

The digital video was the heart of the program, yet it also provided the most challenges. Adobe Premier 4.2 was used for video capture and editing. The video that can be played on most computer systems is considerably lower quality than what people typically see on TV and movies, primarily because high-quality video requires fast systems and lots of space. Yet, observational research coding could not be learned with the use of the typical postage-sized videos with jerky motion that are part of many multimedia programs. We attempted to compromise by capturing the video in $\mathrm{mJPG}$ format and then compressing it with Cinepak's Quicktime codec into $320 \times$ 240 high-color full-motion videos.

In its present form, the program works on three operating systems: Windows $3.1 \mathrm{x}$ and 95 , and Windows NT 4.0. Windows 95 uses the Quicktime 32-bit player, and 3.1 $\mathrm{x}$ and NT 4.0 use the 16-bit player. A version for the Mac is planned for the future. The program should work well on most machines purchased within the last 2 years. However, on older machines, there are limitations. For the classroom component, one would need a projection system or LCD panel that could project $640 \times 480$, with a minimum of thousands (high color), and preferably millions, of colors (true color). At the low end, the program will work on a 486-DX2 66- $\mathrm{MHz}$ machine with $16 \mathrm{MB}$ of RAM and a $4 \mathrm{X}$ CD-ROM, but the video cod- ing will be slow. On a Pentium $133 \mathrm{MHz}$ (2-MB video, 6X CD-ROM, and $32 \mathrm{MB}$ of RAM), the videos look quite natural.

\section{Initial Courseware Evaluation}

Initial evaluations were encouraging. Two faculty members have now used COR - the first author and one faculty member from outside the development team. Both faculty were enthusiastic about the ease of use and the reaction of the students. Fourteen students from an advanced undergraduate Cognitive Development class and 16 students from a basic research methods class have interacted extensively with COR, using it both in class and on their own. They rated the program on a series of 30 questions covering computer use, lecture concepts, and courseware format. Overall, the responses were positive. In fact, $93 \%$ of the students agreed that "These computer generated presentations were superior to most other means I have seen instructors use to present lecture material." They thought that the courseware provided an excellent preparation for out-of-class observational projects.

Students evaluated the concepts covered in COR on a scale of 1 (strongly disagree) to 5 (strongly agree). They were very positive about using digital video to illustrate the three types of behavioral coding (frequency $=4.76$; duration $=4.72$; interval $=4.77$ ). Most disagreed with the statement that "The instructor should use the chalkboard or overhead projector more to illustrate the research concepts, without the use of computerized presentations" $(M=2.00)$. They were less positive about the clarity of the steps needed in order to calculate $\mathrm{Co}$ hen's kappa $(M=4.05)$ and chi square $(M=4.01)$. Not surprisingly, the 200 -level class had more difficulty with these concepts than did the 400-level class. All students agreed or strongly agreed that "The instructor should continue to use computerized aids in teaching observational research methods" $(M=4.57)$.

The responses to open-ended items also reflected students' generally positive feelings about the program. For example, one student said,

What a fabulous way to learn! I truly wish we would have had this module when I was in 201 (Basic Research Methods) last spring. The video presentations clarified the complexity involved in naturalistic observation and the methods used. The module definitely gives a clear understanding of why and when you would use each type or a combination!

Negative comments focused on a need for more videos with more behaviors to choose from, and difficulty with starting the program in NT 4.0, since some students were not familiar with using NT Explorer to open a program.

\section{Availability}

The courseware would be useful in a variety of courses, including research methods, developmental psychology, and animal behavior. The coding sheets can be used flexibly in conjunction with the instructor's own computer presentations and data analysis software. The current 
version of COR is available on CD-ROM for the cost of $C D$ production, shipping, and handling $(\$ 30)$. Instructors interested in using the software should contact the first author by mail or e-mail.

\section{REFERENCES}

Belsky, J., \& Rovine, M. J. (1988). Nonmaternal care in the first year of life and the security of infant--parent attachment. Child Development, 59, 157-167.

CASHIN, W. (1990). Students do rate different academic fields differently. In M. Theall \& J. Franklin (Eds.), Students ' ratings of instruction: Issues for improving practice (pp. 113-121). San Francisco: JosseyBass.

Drake, M. A., \& STAHL, J. M. (1995). Design and use of a U.S. census data computer laboratory for teaching undergraduate research methods. Behavior Research Methods, Instruments, \& Computers, 27, 285-288.

Eisenberg, N., Fabes, R. A., Miller, P. A., Fultz, J., Mathy, R. M., SHELL, R., \& RENO, R. R. (1989). The relations of sympathy and personal distress to prosocial behavior: A multimethod study. Journal of Personality \& Social Psychology, 57, 55-66.
Goolkasian, P. (1996). Getting started with multimedia. Behavior Research Methods, Instruments, \& Computers, 28, 279-281.

Graham, J., Alloway, T., \& Kramer, L. (1994). Sniffy, the virtual rat: Simulated operant conditioning. Behavior Research Methods, Instruments, \& Computers, 26, 134-141.

MCGOVERN, T. V. (ED.) (1993). Handbook for enhancing undergraduate education in psychology. Washington, DC: American Psychological Association.

Noldus Information TeChNology (1997). The Observer: Videotape analysis system [Computer software]. Sterling, VA: Author.

Rosen, E. F., \& PetTy, L. C. (1996). Selecting an appropriate multimedia authoring language. Behavior Research Methods, Instruments, \& Computers, 28, 286-290.

Stoloff, M., \& Couch, J. (1992). Computer use in psychology: A directory of software. Washington, DC: American Psychological Association.

VANDERSTOEP, S., \& Shaughnessy, J. (1997). Taking a course in research methods improves reasoning about real-life events. Teaching of Psychology, 24, 122-124.

(Manuscript received October 13, 1997; revision accepted for publication January 8 , 1998.) 